\title{
WELFARE OF THE BRITISH FACTORY WORKER
}

$\mathrm{A}^{\mathrm{N}}$ $\mathrm{N}$ important adjournment debate on accidents at work, opened in the House of Commons by Mr. Elwyn Jones on December 21, directed attention to a disturbing position which, it was urged, is not fully reflected in the reports of the Chief Inspector of Factories.

Although the last report showed that in 1960 there were 190,000 accidents causing death or disability from work for more than three days, an increase of 9 per cent in 1959, and of these 675 were fatal, compared with 600 in 1959 . This included a 15 per cent increase in reported accidents to young persons and of 17 per cent in accidents to boys (to totals of 12,500 and nearly 10,000, respectively). Dr. Barnett Stross, pointing out that the Chief Inspector himself had admitted the need for more reliable information about accidents which are not reported, said that the spells of certified incapacity arising from accidents shown by the Minister of Pensions and National Insurance were much greater than the number of accidents reported to the factory inspectors. Dr. Stross arrived at a total of 235,000 accidents for a number of groups and suggested that the true total for 1960 was probably at least 250,000 , the worst offenders being in the 83 per cent of factories employing only 1-25 people.

Welcoming the announcement that the Inspectorate was to be increased by some 30 inspectors, Dr. Stross suggested that an increase of about 350 was needed and that more research was required into the prevention of accidents and more co-ordination and co-operation between the Government departments involved. Mr. Jones had already emphasized that accidents were caused and did not just happen, and Dr. Stross, fully supporting this view, argued that it would be well worth while to incur expenditure of a further few hundred thousand pounds to avoid the loss of up to $£ 300$ million a year through accidents apart from the aspects of human suffering. Mr. R. E. Prentice also supported Dr. Stross in his plea for a further increase in the factory inspectorate and urged also a more vigorous policy of education, among trade unions as well as employers, fuller use of public relations, and like Mr. Jones, referred to the opportunities offered by a proper apprenticeship system.

The Parliamentary Secretary to the Ministry of Labour, Mr. Alan Green, welcomed the debate, and in replying for the Government agreed that 1960 had been a thoroughly bad year from the point of view of accidents and that everything possible should be done to see that industry was made safer for those working in it. While he was alive to the vital importance of enforcing the requirements of the Factories Act, he did not consider that an increase in the size of the inspectorate would itself provide a cure. The latest increase would bring its strength to 393 in the general inspectorate and to 87 in the specialist branch, and there were limits to the speed and to the size by which an inspectorate of this kind could be increased if its essential characteristics were to be maintained. He did not believe, moreover, that compulsory safety committees were the answer; more good would be done if they were voluntary, and the attention of several important industries was already being directed to the seriousness of the accident problem and the proved value of accident prevention machinery. The Government believed that accident prevention was best approached in industry by industry and that self-help was the most effective method of combating accidents.

Mr. Green pointed out that 65 per cent of all accidents still arose from straightforward carelessness and clumsiness. In 1961, 2,274 safety committees were operating and 4,000 factories had safety officers. The Minister of Labour had recently made two important codes of regulations which for the first time covered the construction industries as a whole, and further codes were being prepared. Farlier this year the Minister of Education had again brought the matter to the attention of local education authorities, particularly in connexion with safety training in schools and technical colleges, and Mr. Green emphasized that employers should recognize their responsibility for giving induction training to young entrants. He concluded by quoting the view of the Industrial Safety Sub-Committee of the National Joint Advisory Council that to secure a further substantial reduction in the incidence of accidents, more extensive, better organized and better informed action by everyone in industry was required, and to this planners, designers, managers, technicians, research workers, supervisors and workers had an important contribution to make.

\section{THE SHIRLEY INSTITUTE}

$\mathrm{T}$ HE annual general meeting of the Cotton Silk and Man-made Fibres Research Association was held on October 12. The chairman, Sir Cuthbert Clegg, and the director of research, Dr. D. W. Hill, addressed the meeting. On October 12 and 13 the laboratories and workrooms of the Association, the Shirley Institute, Didsbury, Manchester, were open for inspection by representatives of member firms of the Association. More than 1,100 visitors attended on the two days.

About forty special exhibits had been arranged eovering most aspects of the Institute's present research programme, which includes both fundamental scientific and technological work. Space permits mention of only a few of the more recent developments at the Institute. In the Spinning Workrooms, for example, the prototype scutcher controller and the sandwich blender were on view. The former allows for completely automatic control of lap weight, certainly within the usual eight-ounce tolerance and generally within a four-ounce tolerance range, and it can be fitted as a conversion unit to existing scutchers. The latter is again an automatic machine, this time for recovering the lost blending resulting from the omission of stack blending in modern opening lines. High production cards are now being produced, and an assessment of such machines must be made. In the meantime, prelimin- 
ary experiments have been conducted on the effect of speeding-up the ordinary eard with the ultimate object of obtaining information that will enable the industry, with its 20,000 cards to exploit most economically and effectively the modern trends.

In the Sizing Room could be seen the results of some experiments on a new method of fibre laying on sized warps. This is an extension of work on the selfbrushing of warps, which has also been continued to the point where the latest version of the attachment is available commercially.

In the Weaving Shed the latest modifications to the Shirley loom were demonstrated : it has now been fitted with a re-designed positive dobby using a paper pattern control in place of the earlier system using lags and pegs, and these modifications enable the dobby to operate at high speeds. Work on loom mechanisms, especially as they are affected by the demands for ligh speeds, has been carried out in collaboration with British Northrop Ltd. Visitors were shown a device for the hot-stretching of tyre cords which also shows considerable promise in other directions where the rapid application of dry heat at a uniform temperature is desirable : this is the fluidized bod. Present work is concentrated on the dyeing of fabrics from synthetic fibres such as nylon or 'Terylene' where the only major technical problem remaining is the application of the dye liquor in suitable form and suitable quantity. Arrangements have been made for the fluidized bed to be incorporated in a commercial frame for the heat treatment of bulked yarns at high speed.

The increasing shortage of water, its high cost, and the increasing difficulty and expense of disposing of effluent all make the efficient washing of textiles in finishing of great importance. It has been estimated that the cost of water may well be trebled in the next 5-10 years. A theoretical basis for the removal of water-soluble impurities has been established by Institute staff, together with some practical confirmation, and this will be extended as soon as possible to full-scale operation and extended to the removal of insoluble contamination. Much work remains to be done here to provide the most efficient and economical procedures, but good progress has been made.

Chlorite bleaching, which is becoming increasingly important, has been the subject of much work at the Institute in recent years. Conditions for its use under non-corrosive and non-poisonous conditions have been established, and the use of activators of different kinds has been investigated resulting in the development of a now method of activating ehlorite which permits the use of a cold-pad method for chlorite bleaching. This is particularly valuable for blends including fibres sensitive to the more normal vigorous bleaching processes.

The programme of work on fabrics from blended fibres has now reached the stage where the Institute can expect to be able to forecast most of the properties of such fabrics from a knowledge of the behaviour of the individual fibres. From now on, therefore, it will be necessary to work only on the individual properties of yarns and fabrics from 100 por cont single fibre form.

As part of a general investigation of the relation between the molecular constitution of fibres and their textile properties, a number of silk fibroins of different origins have been examined by chemical and X-ray methods. Fundamental investigations of the geometrical structure of continuous filament yarns and of the effect of twist on tensile properties have also been undertaken.

Fundamental work on stiffness, crease-resistance and crease-recovery is being carried out at the Institute, and exhibits were concerned with the relations between fibre, yarn and eloth stiffness. the effect of crease orientation on creasability, the effect of time in the measurement of creasability, ageing after finishing, and the measurement of the forces involved in creasing and crease-recovery.

The foregoing are but some of the many aspects of the Institute's work which were on show. The attendance figures, coupled with the onthusiasm and interest of the visitors to the open days, contributed to their success and are both an encouragement to the research staff and proofs of the continuing esteem in which the Institute is held.

\section{SOLAR FLARES}

COLAR flares were described by Prof. M. A. Ellison $S$ in his Friday Evening Discourse at the Royal Institution on October 23 as catastrophic events in the hot, outer layers of the Sun. These have immediate repercussions in our terrestrial atmosphere 93 million miles away. A flare emits simultaneously both waves and particles; but the waves, irrespective of wave-length, travel with the speed of light and arrive together after an interval of $8 \frac{1}{2}$ min., whereas the particles lag behind, arriving after various intervals depending on their individual speeds. The particles consist of three main recognizable groups. The first, the magnetic storm particles, which reach our atmosphere after some $20-50 \mathrm{hr}$., consist mainly of ionized hydrogen atoms--protons - and electrons, and form a plasma. Of low energy and guided by tho Earth's magnetic field these particles enter our atmosphere in the regions close to the magnetic poles, setting up powerful electric currents in the ionosphere and hence magnetic storms. In addition, they excite the atoms and molecules in the atmosphere and produee tho colourful displays of the auroræ.
The second group of particles, consisting mainly of protons with energies of $10^{7}$ to $4 \times 10^{8} \mathrm{eV}$., take about $1 \mathrm{hr}$. or more to arrive, and are to be regardod as cosmic rays. They enter the atmosphere at locations within $30^{\circ}$ of the two geomagnetic poles and give rise to intense ionization in the $D$-region of the ionosphere, producing polar-cap black-outs of incoming cosmic radio noise in the very-high-frequency band. They do not possess, however, sufficient energy to penotrate to the lower levels of the atmosphere or to generate secondary particles and thus can be studied directly only from high-flying balloons or indirectly from the absorption effects of radio waves which their ionization produces in the polar regions.

On twelve occasions during the past twenty yoarsthe first on February 28, 1942-meson monitors (maximum response to particles of about $10^{10} \mathrm{eV}$.) and noutron monitors (maximum response to particles of about $10^{9} \mathrm{eV}$.) located at ground-level have recorded sudden increases of cosmic-ray intonsity. The showors of primary particles responsible for the increases came directly from the Sun and all occurred 